\title{
Benefícios à saúde humana do consumo de isoflavonas presentes em produtos derivados da soja
}

\author{
Mayara Miranda ZAKIR ${ }^{[1] \mathrm{e}}$ Irene Rodrigues FREITAS ${ }^{[1 ; *]}$ \\ ${ }^{[1]}$ Universidade do Oeste Paulista, Campus II. Rodovia Raposo Tavares, Km 572, Bairro Limoeiro 19.067-175 - Presidente Prudente, São Paulo, \\ Brasil. mayarinha_zakir@yahoo.com.br
}

\section{INFORMAÇÕES}

Convite em: 02/06/2015

Enviado em: 22/07/2015

Aceito em: 12/09/2015

Publicado em: 27/09/2015

Document Object Identifier

$10.18607 /$ jbfs.v2i3.50

Termos de indexação:

Leguminosas

Fitoestrógenos

Alimentos funcionais

*Autor para correspondência

irenefreitas@gmail.com

\section{RESUMO}

As leguminosas utilizadas na alimentação de diversas populações ao redor do mundo são importantes fontes de energia e diversos nutrientes. A soja (Glycine max) que apresenta uma composição quase completa, vem se destacando como um alimento funcional, pois além de sua função normal de nutrição, ainda apresenta diversos benefícios para a saúde. O grão de soja possui os compostos bioativos que estão sendo amplamente estudados, pois visam a prevenção e a redução dos riscos de desenvolvimento de d oenças crônicas como diabetes, colesterol, hipertensão arterial, cânceres entre outros. As isoflavonas são compostos químicos pertencentes à classe dos fitoestrógenos, as principais isoflavonas encontradas na soja são a daidzeína, a genisteína e a gliciteína. Evidências científicas sugerem que as isoflavonas, desempenham um papel importante na prevenção e controle de doenças crônicas. Devido ao crescente interesse da população em consumir alimentos saudáveis, a indústria alimentícia vem se dedicando a desenvolver novos produtos, cujas funções pretendem ir além do fornecimento dos nutrientes básicos à alimentação humana, esses alimentos são conhecidos como alimentos funcionais. Dessa forma torna-se importante o estudo dos benefícios que o consumo de diferentes produtos alimentícios à base de soja pode oferecer na prevenção e no controle de diversas patologias. O presente trabalho tem como objetivo incentivar o consumo dos produtos derivados de soja, devido aos efeitos benéficos que a ação das isoflavonas presente na leguminosa oferece ao organismo humano.

\section{Benefits to human health in consumption of isoflavones present in soybean products}

\begin{abstract}
The legumes used for feeding the diverse populations around the world are important source of energy and various nutrients. Soybean (Glycine max) which features an almost complete composition, has been highlighted as a functional food due to its many health benefits in addition to its normal function of nutrition. The soybean has bioactive compounds that are being widely studied for preventing and reducing chronic disease development risks such as diabetes, cholesterol, hypertension, cancers and others. Isoflavones are chemical compounds belonging to the class of phytoestrogens. The main isoflavones found in soy are daidzein, genistein and glycitein. Scientific evidence suggests that isoflavones play an important role in the prevention and control of chronic diseases. Due to the growing interest of the population to consume healthy foods, the food industry has been dedicated to developing new products whose functions aim to go beyond the provision of basic nutrients for human consumption; these foods are known as functional foods. Thus it becomes important to study the benefits that consumption of different food products soy can offer in the prevention and control of various pathologies. The present study aims to encourage the consumption of soybeans and its derivatives, due to the beneficial effects as the action of isoflavones present in legume provides the human body.
\end{abstract}

Index terms: legumes, phytoestrogens, functional foods

Copyright: () 2015 JBFS all rights. This is an open-access article distributed under the terms of the Creative Commons Attribution License, which permits unrestricted use, distribution, and reproduction in any medium, provided the original author and source are credited.

Financiamento: Os autores reportam que não houve suporte ou auxílio financeiro para a realização da pesquisa.

Conflito de interesse: Os autores declaram que não há conflito de interesse.

Como referir esse documento (ABNT):

ZAKIR, M. M.; FREITAS, I. R. Benefícios à saúde humana do consumo de isoflavonas presentes em produtos derivados da soja. Journal of Bioenergy and Food Science, Macapá, v.2, n.3, p.107-116, jul./set., 2015. http://dx.doi.org/10.18607/jbfs.v2i3.50 


\section{INTRODUÇÃO}

As leguminosas são importantes fontes de energia e proteína e fazem parte do hábito alimentar de diversas populações ao redor do mundo, sabe-se que as proteínas são essenciais à dieta humana, sendo que o seu valor biológico e nutricional dependem da quantidade, digestibilidade, absorção e utilização dos aminoácidos que a compõem $[1,2]$. Com uma composição quase completa, a soja (Glycine max) é uma leguminosa caracterizada como fonte de proteínas, carboidratos, lipídeos, vitaminas, ácidos graxos saturados e insaturados e fitoquímicos importantes em diferentes atividades metabólicas como as isoflavonas, além de ser uma boa fonte de minerais como ferro, potássio, magnésio, zinco, cobre, fósforo, manganês e vitaminas do complexo $\mathrm{B}$ e fornecer diferentes nutrientes ao organismo, é ainda, considerada um alimento funcional, pois apresenta diversos benefícios para a saúde, auxiliando na redução do risco de desenvolvimento de doenças crônicas e degenerativas $[2,3]$.

Evidências científicas através de estudos em humanos, animais e sistemas de culturas de células sugerem que as isoflavonas, que são compostos presentes na soja, especificamente a genisteína e a daidzeína desempenham um papel importante na prevenção de doenças crônicas, apresentando um efeito anticancerígeno e atividade antioxidante, com isso, este componente pode trazer benefícios no controle e prevenção de doenças como câncer, diabetes mellitus, osteoporose e doenças cardiovasculares devido a mecanismos como diminuição nos níveis de colesterol total decorrente do aumento na atividade de receptores das lipoproteínas de baixa densidade (LDL) [4].

Mesmo sendo cultivada no Brasil desde 1914, até pouco tempo, a soja ainda era um produto sem muita participação na alimentação dos brasileiros, no entanto, observa-se atualmente uma mudança no hábito alimentar da população com a introdução de produtos naturais ou pouco industrializados, aumentando também, o consumo de alimentos derivados ou à base de soja [5].

Segundo os autores Behrens e da Silva [6] estudos mostraram que a relação entre dieta e saúde, somadas ao crescente interesse de alguns indivíduos em consumir alimentos saudáveis, têm levado a indústria alimentícia a desenvolver novos produtos, cujas funções pretendem ir além do fornecimento dos nutrientes básicos à alimentação humana. Esses produtos são conhecidos como alimentos funcionais e representam um novo segmento dentro do mercado de alimentos. Devido ao fato de que a soja é um dos principais produtos agrícolas comercializados no mundo, torna-se importante o estudo de suas tecnologias de produção, sua aplicação na indústria e na fabricação de diferentes produtos alimentícios e quais os benefícios que o consumo regular de alimentos funcionais, principalmente, e que contém isoflavonas em sua composição, pode oferecer à saúde da população.

Este trabalho tem como objetivo descrever quais os benefícios que o consumo das isoflavonas pode oferecer à saúde humana.

\section{COMPOSIÇÃO E CARACTERÍSTICAS DO GRÃO DE SOJA}

A soja produzida em grande escala no Brasil é um grão pertencente à família do feijão, apresenta formato arredondado e cor amarelada, possui um excelente valor nutritivo, é rica em proteínas, fibras, vitaminas e minerais e possui em sua composição cerca $40 \%$ de proteínas de boa qualidade, $20 \%$ de lipídios, $5 \%$ de minerais e $34 \%$ de carboidratos, além de minerais como: cálcio, fósforo, ferro, magnésio, sódio, potássio e cobre. Pelo fato de desempenharem um papel importantíssimo como constituintes da estrutura de vários tecidos (principalmente ósseos), assim como por serem reguladores de atividades enzimáticas e transportadores de componentes das membranas celulares, a presença dos minerais se torna essencial na dieta diária $[7,8]$.

Os lipídios presentes em quantidade elevada na soja são substâncias com baixa solubilidade em água e que quando hidrolisadas na digestão fornecem ao organismo ácidos graxos que ajudam na absorção das vitaminas $\mathrm{A}, \mathrm{D}, \mathrm{E}$ e $\mathrm{K}$, além de protegerem e isolarem órgãos e tecidos [9]. A vitamina $\mathrm{E}$ é a principal vitamina lipossolúvel presente no grão de soja e é um tocoferol com função antioxidante, que oferece proteção contra a ação dos radicais livres e fortalece o sistema muscular e reprodutor, a falta ou a diminuição dos níveis de vitamina $\mathrm{E}$ no organismo, provoca alterações neurológicas como diminuição dos reflexos, da sensibilidade vibratória e de percepção. Embora não seja comum, no grão de soja também são encontradas as vitaminas hidrossolúveis, observa-se a presença da Tiamina (B1), Riboflavina (B2), Niacina (B3) e Piridoxina (B6), além do ácido fólico. Estas vitaminas melhoram a circulação sanguínea, favorecem o desenvolvimento físico, ajudam no metabolismo de proteínas, gorduras e carboidratos, agem no sistema nervoso através da formação de substâncias mensageiras como a adrenalina, auxiliam na redução do colesterol e 
também estimulam as funções defensivas do cérebro [10].

O grão de soja possui também os chamados compostos bioativos que estão sendo amplamente estudados, pois visam a prevenção e a redução dos riscos de desenvolvimento de doenças crônicas não transmissíveis como diabetes, colesterol, hipertensão arterial, cânceres entre outros [7].

O consumo de soja e sua relação com a saúde humana têm sido estudados devido às características nutricionais desse alimento, tanto pelo seu elevado teor de proteínas de boa qualidade nutricional, quanto por seu conteúdo significativo de minerais e fibras e ainda, sua quantidade reduzida de gordura saturada e ausência de colesterol [11]. Pesquisas sugerem a presença de compostos fitoquímicos na soja, o que a torna um alimento funcional capaz de atuar na prevenção dos sintomas da menopausa, enquanto outros estudos afirmam que o consumo da soja ajuda a evitar o desenvolvimento de alguns tipos de tumores, como o de próstata, de mama e do trato urinário $[11,12]$.

\section{ALIMENTOS FUNCIONAIS}

Alimentos funcionais são aqueles que ao serem consumidos como parte da dieta usual, além das suas funções nutricionais, produzem também alguns efeitos metabólicos e fisiológicos através do desempenho de algum nutriente específico, sendo também seguro para o consumo sem supervisão médica. Uma definição simples e prática de alimentos funcionais é a de que alimentos funcionais são alimentos ou ingredientes alimentares que podem fornecer um benefício à saúde além dos tradicionais nutrientes já contidos $[8,13,14]$. O termo alimento funcional surgiu no Japão por volta de 1980, logo após o governo japonês iniciar um programa de redução de custos de seguro saúde e medicamentos, atividade que foi especialmente voltada à população que estava se tornando mais velha, procurando, dessa forma, incentivar metodologias que pudessem melhorar a perspectiva da saúde em longo prazo. Assim, foi implantado um programa chamado Foshu - Foods for Specified Health Use - comida para uso específico de saúde, onde foram avaliados quais os alimentos que trariam benefícios comprovados à saúde da população, cumprindo funções específicas no organismo [13].

Os alimentos funcionais apresentam-se para o consumo humano de duas formas: naturais e artificiais. As formas naturais dos alimentos funcionais são aquelas que contem ácidos graxos (linoleico, ômega-3 e 6 e limonóides), fibras, probióticos (lactobacilos e bifidobactérias), compostos fenólicos (resveratrol, isoflavona e zeaxantina) e carotenoides (betacaroteno, licopeno e luteína). Os artificiais são aqueles fabricados por empresas especializadas e autorizadas. Alguns alimentos enriquecidos com vitaminas e minerais podem ou não ser considerados como funcionais, uma vez que para ser considerado funcional o alimento deve exercer algum efeito adicional comprovado sobre a saúde ou sobre alguma doença crônica, caso contrário nada mais é do que um alimento comum. Alguns alimentos industrializados também podem ser considerados funcionais, porém estes geralmente possuem concentrações muito pequenas dos componentes funcionais [14].

A ANVISA (Agência Nacional de Vigilância Sanitária) determina normas e procedimentos para registrar os alimentos funcionais no Brasil. Para lançar um produto no mercado com registro de alimento com alegações de propriedades funcionais, a empresa deve seguir a legislação do Ministério da Saúde e apresentar um relatório técnico-científico com diversas informações que comprovem seus benefícios e a garantia de segurança para seu consumo [15].

Uma dieta rica em alimentos funcionais oferece grandes benefícios à saúde do indivíduo, dando mais disposição e energia, garantindo bem estar físico mental e psicológico, que contribui para uma melhoria da qualidade de vida. Dentre os principais benefícios relacionados ao consumo desse tipo de produto, destacam-se o reforço dos mecanismos de defesa imunológicos, prevenção ou tratamento de determinados tipos de patologia ou disfunção, melhoria das condições físicas e mentais e retardo no processo de envelhecimento do organismo [13]. Para que os benefícios do consumo dos alimentos funcionais sejam alcançados de maneira eficaz, é preciso que o consumo desses alimentos seja realizado de forma regular como parte da dieta usual do indivíduo, o que se torna possível através de uma maior ingestão de frutas, vegetais e cereais integrais, visto que são as principais fontes dos componentes ativos dos alimentos funcionais, redução do consumo de carne vermelha, alimentos industrializados e enlatados e um aumento dos derivados da soja e peixes, que são ricos em ômega-3. Os efeitos que os alimentos funcionais exercem sob a saúde vêm sendo estudados, principalmente, nas patologias, como o câncer, diabetes, hipertensão, Mal de Alzheimer, doenças ósseas, cardiovasculares, inflamatórias e intestinais [14].

Os alimentos funcionais representam uma das tendências para o mercado de alimentos, tanto no Brasil quanto no exterior, cada vez mais vem 
sendo realizados fóruns de discussão a respeito de novas descobertas e usos dos alimentos funcionais. $\mathrm{O}$ crescente interesse das indústrias por este tipo de alimentos está relacionado diretamente às atuais necessidades em se combater os problemas de saúde da população e também devido ao aumento da média de vida da população e o consequente aumento da consciência dos consumidores que desejam melhorar a qualidade de vida optam por hábitos saudáveis [13, 16]. Vale lembrar que os alimentos funcionais não curam doenças, apenas previnem o seu aparecimento e caso isso aconteça ajudam o organismo a combatê-las de maneira mais eficaz. Esses alimentos não devem ser utilizados como remédios, mas, devem ser incorporados à dieta para que possam ser consumidos diariamente, ajudando no fortalecimento do organismo [14].

Atualmente os consumidores têm procurado se informar cada vez mais a respeito dos alimentos funcionais, buscando modificar seus hábitos alimentares com vista a melhorias na saúde. Esse comportamento contribui para a popularização dos produtos com alegações de benefícios à saúde [17]. Nesse contexto de alimentos com alegações de propriedades funcionais destacam-se a soja e seus derivados [18]. ISOFLAVONAS E SEUS BENEFÍCIOS À
SAUUDE

A)<smiles>C[C@]12CC[C@@H]3c4ccc(O)cc4CC[C@H]3[C@H]1CC[C@@H]2O</smiles>

C)<smiles>O=c1c(-c2ccc(O)cc2)coc2cc(O)ccc12</smiles>

O grão de soja é rico em fitosteróis na forma de isoflavonas, as quais se relacionam quimicamente com os hormônios esteroides do corpo, além disso, o consumo diário da leguminosa tem sido associado à prevenção e ao tratamento de disfunções como hipertensão, hipercolesteronemia e osteoporose $[2,8,11]$.

As isoflavonas são compostos químicos fenólicos que pertencem à classe dos fitoestrógenos devido a sua estrutura química ser bastante semelhante ao estrógeno humano e estão amplamente distribuídos no reino vegetal, estas se comportam como estrógenos verdadeiros, ligandose aos receptores de estrógeno, mas não são capazes de causar os mesmos efeitos colaterais. As concentrações destes compostos são relativamente maiores nas leguminosas e especialmente na soja, as principais isoflavonas encontradas na soja são a daidzeína, a genisteína e a gliciteína (Figura 1) que geralmente estão presentes de forma conjugada a glicosídeos em alimentos. As isoflavonas apresentam um efeito de equilíbrio nos níveis de estrógenos endógenos, que são benéficos durante toda a vida da mulher.

Na pós-menopausa, quando as concentrações endógenas de hormônios diminuem, os receptores de estrógeno ficam mais disponíveis, o que favorece uma fraca ação estrogênica das isoflavonas $[19,20,21]$.

B)<smiles>O=c1c(-c2ccc(O)cc2)coc2cc(O)cc(O)c12</smiles>

D)<smiles>COc1cc2c(=O)c(-c3ccc(O)cc3)coc2cc1O</smiles>

Fonte: HE; CHEN (2013).

Figura 1 - Estrutura química do 17 - $\beta$ Estragiol(A), Genisteína(B), Daidzeína(C) e Gliciteína(D) 
Dentre as substâncias presentes nos alimentos, os fitoesteróis presentes nos óleos vegetais - óleo de soja, gergelim, semente de girassol e leguminosas promovem a redução da absorção de lipoproteínas de baixa densidade (LDL) conhecido como "mau colesterol" e auxiliam também no alivio dos sintomas da tensão pré-menstrual ao evitar a queda nos níveis de estrogênio. Os fitoestrógenos como a Isoflavona da soja beneficiam a saúde óssea, previnem doenças cardiovasculares, câncer de mama e próstata e o Licopeno é anticarcinogênico, previne o surgimento de tumores de próstata, pulmão e intestino. O ômega-3 apresenta função cardioprotetora e a hipercolesterolemia. O ômega 6 presente nos óleos vegetais como azeite, óleo de canola, milho, girassol, nozes, soja e gergelim, também atua como protetor contra diversos tipos de doenças [16]. As isoflavonas podem funcionar como repositores hormonais naturais, sua ação está baseada na capacidade de ligação com os receptores de estrógeno, atuam na translocação para o núcleo da célula e induzem a transcrição do gene específico, que pode incluir a divisão celular. Uma das formas de ação das isoflavonas, particularmente da genisteína, é o bloqueio de fosforilações específicas como a do fator NFkB que participa em processos inflamatórios e na osteoporose. O consumo de isoflavonas provoca efeito antiangiogênico, inibição da DNA topoisomerase e seus efeitos antioxidantes em lipídios. Agem sobre lipoproteínas e DNA, bem como no transporte de glicose e em vários sistemas de transportes de íons, podem atuar tanto como agonistas quanto antagonistas do estrógeno ou como moduladores dos receptores seletivos de estrógeno. Seu efeito varia dependendo do órgão do corpo humano, do tipo de célula, da concentração de isoflavonas, da condição hormonal, idade, etc. [22].

$O$ grande interesse na presença dos fitoestrógenos e nos potenciais benefícios que uma dieta rica nestes compostos pode estar relacionado com o controle de muitas doenças crônicas. Estudos têm mostrado que o consumo regular de soja pode contribuir para a redução do risco da ocorrência de algumas enfermidades como as doenças cardiovasculares, alguns tipos de câncer, osteoporose e sintomas da menopausa [12]. Acredita-se, que a menor incidência de sintomas da menopausa, osteoporose e cânceres estrógenodependentes em mulheres esteja relacionada à ingestão de isoflavonas [8].

No entanto, o maior interesse dos pesquisadores está relacionado com a farmacologia e fisiologia das isoflavonas, pois esses compostos apresentam estrutura não esteroidal, mas comportam-se como estrógenos na maioria dos sistemas biológicos, além de serem as mais abundantes dentre os fitoestrógenos. Em adição à sua atividade anti-estrogênica, estes compostos possuem diversas propriedades biológicas (atividade antioxidante, inibição da atividade enzimática entre outras) que podem influenciar muitos processos bioquímicos e fisiológicos [19].

A evidência de que as isoflavonas protegem o organismo humano contra diversas doenças crônicas está baseada em estudos experimentais e epidemiológicos. Em humanos, estudos epidemiológicos realizados em populações ocidentais expostas a quantidades limitadas de isoflavonas de soja: daidzeína e genisteína, na dieta, mostram claramente uma maior incidência de alguns tipos comuns de câncer, como de mama, próstata e cólon e doenças cardiovasculares [23].

\section{PRODUTOS DERIVADOS DA SOJA}

Devido ao crescente aumento na procura por alimentos à base de soja no Brasil, diversos produtos têm sido lançados no mercado, sendo que através do processamento da soja se dá origem a diferentes matérias-primas como farinhas de soja, extratos hidrossolúveis e proteínas texturizadas que podem ser utilizados na produção de alimentos que fazem parte da dieta ocidental [24].

Sabe-se que $60 \%$ dos alimentos processados disponíveis nos supermercados norte-americanos contêm soja, no Brasil, a quantidade de soja consumida através dos alimentos industrializados não é muito diferente da encontrada nos Estados Unidos e aumenta progressivamente, esse aumento é resultado da forte estratégia de marketing, com o apoio de pesquisas científicas, que tem como principal foco o consumidor preocupado com questões de saúde. Entre os principais produtos produzidos à base de soja estão os sucos à base de extratos de soja, hambúrgueres vegetarianos, embutidos de carne e frango, bolos, sorvetes, milkshakes, barras de cereais e até água com sabor de frutas [12].

O óleo de soja quando comparado com outros tipos de óleos vegetais apresenta uma maior quantidade de gorduras, o conteúdo lipídico extraído do grão processado representa de $14 \%$ a $20 \%$ da composição nutricional da soja, encontramse predominantemente gorduras poli-insaturados (58\%), monoinsaturados (23\%) e uma pequena quantidade de saturados (15\%). O óleo de soja é amplamente utilizado na indústria de alimentos, dietoterapia hospitalar, unidades de alimentação e nutrição e no consumo domiciliar, esse tipo de óleo possui alta concentração de ácido graxo linoleico - 
ácido graxo $\Omega-6(51 \%)$ e até $8 \%$ de ácido graxo linolênico - ácido graxo $\Omega-3$, considerado benéfico na diminuição dos riscos de doenças cardíacas [25].

Na região asiática a soja é utilizada em uma ampla variedade de alimentos tradicionais e alguns mais modernos. No Japão, por exemplo, o tofu é o alimento à base de soja mais consumido entre a população, presente em praticamente todas as refeições, o tofu pode ser encontrado na sopa de missô (missoshiru em Japonês) servida no almoço, frito cru, cozido em sopas ou em molhos, cozido a vapor, recheado com diferentes ingredientes, ou fermentado como picles, também é consumido em sobremesas e outros tipos de preparações alimentícias. O missô é mais um produto fermentado consumido diariamente por muitos japoneses, em caldos de sopas, molhos para saladas e coberturas de alimentos [26].

Um produto que vem ganhando destaque nos últimos anos é o extrato hidrossolúvel de soja (EHS), ou o popularmente conhecido "leite" de soja, para as pessoas intolerantes a lactose, o EHS pode ser utilizado para substituir o leite de vaca. Segundo o Instituto Nacional de Doenças Digestivas, Renais e Diabetes (EUA) cerca de 75\% da população mundial é intolerante à lactose, no entanto, se considerássemos apenas a quantidade de proteínas, essa substituição seria perfeita, porém, o teor de cálcio no EHS é deficiente, sendo o leite de vaca a principal fonte desse mineral [8]. Visando tornar o extrato de soja cada vez mais atrativo aos consumidores, novas tecnologias têm sido empregadas para melhorar as suas características sensoriais e nutricionais [17].

O "leite" de soja pode ser encontrado de diversas formas: na forma tradicional, aromatizado, suplementado com vitaminas, açúcar e minerais como o cálcio, que não está presente na soja, mas pode este mineral pode ser adicionado ao produto através dos processos de industrialização, a adição de vitaminas e minerais melhora o seu valor nutricional e a adição de sabores melhora sua aceitação no paladar dos consumidores [21].

A farinha de soja é um novo produto que vem sendo utilizado na fabricação de massas diversas como substituição à farinha de trigo, que apresenta o glúten em sua composição. Sabe-se que as pessoas que possuem a patologia denominada doença Celíaca, são intolerantes ao glúten e não podem consumir produtos à base de trigo, aveia, centeio e cevado, dessa forma, a farinha de soja pode ser utilizada como forma de substituição das farinhas tradicionais na fabricação de massas diversas [7].
O concentrado proteico de soja é um produto utilizado na fabricação do "leite de soja" e preparado a partir da farinha desengordurada, o seu processo de obtenção baseia-se na insolubilização da maioria das proteínas com a exclusão parcial dos carboidratos, sais minerais e outros componentes solúveis típicos da farinha, que resulta em um produto com elevado teor de proteína. No caso da soja, o teor mínimo de proteína para o concentrado proteico deve ser de $70 \%$. No caso de isolado proteico de soja, o produto deve conter no mínimo 90\% de proteína em base seca [27].

A lecitina de soja é resultante do processo de desodorização do óleo de soja e possui grande valor comercial, pois é uma substância amplamente utilizada na indústria farmacêutica e de alimentos como emulsionante em chocolates, tornando-os solúveis em leite, por exemplo. A lecitina é um subproduto da soja indicada como auxiliar na manutenção de células nervosas, assim como para pessoas com problemas de hipercolesterolemia, possui também efeito no combate a obesidade, prevenção de derrames e enfartes e favorece o equilíbrio da pressão arterial. A lecitina também é produzida pelo organismo, porém em quantidade insuficiente. Entre as leguminosas existentes, a soja é a que possui maior fonte de lecitina [28].

\section{BENEFÍCIOS DO CONSUMO DE PRODUTOS À BASE DE SOJA}

Segundo dados da OMS (Organização Mundial da Saúde), as doenças crônicas não transmissíveis são responsáveis por $72 \%$ das mortes ocorridas no Brasil e a nível mundial as doenças crônicas não transmissíveis são responsáveis por $60 \%$ dos casos de mortes. Além disso, $80 \%$ de problemas prematuros do coração, acidente vascular encefálico (AVE), Diabetes tipo II e 40\% dos casos de câncer poderiam ser evitados através da adoção de hábitos alimentares adequados, diminuição no uso de tabaco e atividade física regular [16].

Devido ao crescente interesse da população em consumir alimentos mais saudáveis, a indústria alimentícia vêm desenvolvendo novos produtos com funções que pretendem ir além do fornecimento de nutrientes básicos e que também satisfaçam o paladar dos consumidores, produtos esses conhecidos como alimentos funcionais. Dentre os alimentos lançados nos mercados e que apresentam alegações de benefícios à saúde encontram-se os alimentos derivados ou à base de soja que apresentam propriedades funcionais [6].

O uso da soja na alimentação varia muito ao redor do mundo, sendo o consumo, mais comum no 
continente asiático do que nos países ocidentais. Os povos desses países consomem principalmente derivados fermentados e peixes e vegetais, enquanto que nas nações ocidentais consomem-se muito mais derivados processados associados a uma dieta rica em carnes e pobre em vegetais. Nos países orientais a soja não é usada para substituir carne, frango ou peixe, mas sim, como complemento da dieta normal, rica em verduras e peixes [26].

Uma das aplicações mais conhecida das isoflavonas diz respeito à pós-menopausa, a terapia de reposição hormonal é frequentemente prescrita para mulheres que se encontram na fase de climatério. Esse tratamento previne a perda da densidade óssea, que pode causar osteoporose, diversos autores relatam que o consumo de isoflavonas deve ser de aproximadamente $50 \mathrm{mg}$ por dia para que ocorram seus efeitos benéficos [2].

O câncer é o crescimento incontrolado de células formando um tumor que, em alguns casos, pode invadir os tecidos adjacentes e se propagar, por processos de metástases, formando tumores secundários em outras partes do corpo. Tem sido demonstrado que as isoflavonas da soja, especificamente a genisteína e a daidzeína, apresentam efeito anticancerígeno. Estudos epidemiológicos demonstraram que em populações que consomem dietas ricas em soja e seus derivados, a incidência de determinados tipos de câncer como de cólon, mama e próstata, principalmente, é menor quando comparada com a incidência em populações que não consomem esses tipos de produtos em suas dietas, acredita-se também, que a suplementação da dieta com certos produtos à base de soja ou derivados, poderia reduzir as taxas de mortalidade por câncer [21].

Os mecanismos pelos quais as isoflavonas inibem a carcinogênese ainda não estão bem definidos, porém, estudos sugerem que seus efeitos protetores podem estar relacionados à inibição de enzimas participantes dos processos de proliferação celular, como a S6-quinase ribossomal, proteína quinase $\mathrm{C}(\mathrm{PKC})$ e enzimas de reparo em geral e DNA topoisomerase II. A recomendação diária de isoflavonas segundo a Food and Drug Administration (FDA) é de 30-60 mg, tanto para mulheres como para homens [29].

O estudo realizado por Weber et al [30] afirma que uma alimentação rica em soja é capaz de diminuir os níveis de testosterona e o peso da próstata. Até alguns anos atrás, uma alimentação rica em soja era somente indicada para as mulheres, devido à sua ação na prevenção do câncer de mama, mas atualmente, em função das isoflavonas possuírem ação nos órgãos sexuais hormôniodependentes de ambos os sexos, vêm sendo recomendado também seu consumo para os homens [29].

Araldi et al [31] observaram a base da alimentação dos homens da América do Norte e a incidência de câncer de próstata, onde foi constatado que os homens que mantém uma dieta rica em isoflavonas apresentam um índice de câncer de próstata significativamente menor do que os homens que não consomem alimentos ricos nesses compostos.

A osteoporose é uma patologia crônica que ocorre quando a taxa de degradação óssea dos osteoclastos excede à sua formação. Estudos epidemiológicos sugerem que a incidência de osteoporose pós-menopausa em mulheres asiáticas é menor do que em mulheres ocidentais, possivelmente devido à elevada ingestão de produtos à base de soja e seus derivados ricos em isoflavonas. Sabe-se que a perda de massa óssea está relacionada com a idade e é maior em mulheres do que em homens. A deficiência hormonal quando associada com os efeitos da menopausa, causa um aumento da taxa de remodelação óssea, provocando um desequilíbrio entre a reabsorção e formação, o que acelera a perda óssea [19, 32].

A relação entre as isoflavonas de soja e o tecido ósseo tem sido estudada há pouco menos de dez anos, dados obtidos através de diversos estudos com animais demonstraram que as isoflavonas de soja possuem efeitos de conservação óssea na retenção de massa óssea após ovariectomia [32]. O possível papel desempenhado pelas isoflavonas de soja na modificação de massa óssea humana é de que os suplementos de proteína de soja enriquecidos com isoflavonas atenuam a perda óssea na pós-menopausa e também na prémenopausa em mulheres. O consumo de soja também tem sido associado à redução de doenças cardiovasculares, em especial da arteroesclerose em animais. Evidências epidemiológicas sugerem também, que populações que consomem dietas ricas em soja e seus produtos apresentam uma menor taxa de mortalidade por doenças coronarianas [19].

Os mecanismos pelos quais a soja e as isoflavonas promovam uma ação protetora contra doenças cardiovasculares ainda não estão bem definidos, porém, vários mecanismos de proteção têm sido propostos como, por exemplo, uma diminuição nos níveis de colesterol total, devido ao aumento na atividade de receptores de LDL, atividade antioxidante, atividade anti-proliferativa e anti-migratória sobre as células musculares lisas, 
prevenção da formação de trombos, manutenção da reatividade vascular normal e melhora na função endotelial. As isoflavonas têm sido utilizadas na prevenção de doenças cardiovasculares, pois melhoram o perfil lipídico dos pacientes, reduzindo os níveis de triglicerídeos, colesterol total e LDLcolesterol e aumentando os níveis das lipoproteínas de alta densidade (HDL) [20].

O diabetes mellitus é uma patologia caracterizada por níveis elevados de glicose no sangue quando o organismo está em jejum, acompanhado por alterações no metabolismo de carboidratos, lipídios e proteínas, sendo essas alterações uma consequência do déficit da secreção ou da ação da insulina. Sabe-se que a insulina é o principal hormônio que regula o metabolismo da glicose, nas células, a insulina ativa o transporte de glicose e aminoácidos, o metabolismo de glicogênio e lipídios, a síntese proteica e a transcrição de genes específicos. As formas clínicas mais frequentes do diabetes são o diabetes mellitus insulino dependente e o diabetes mellitus não insulino dependente, que é o tipo mais frequente entre a população. A vida dos pacientes diabéticos é acompanhada de numerosas complicações tanto metabólicas - hiperglicemia, hipoglicemia, dislipidemia; quanto vasculares - nefropatias, retinopatias e neuropatias [19].

Os mecanismos pelos quais as isoflavonas exercem efeitos no controle do diabetes mellitus ainda não estão definidos, sabe-se que a genisteína é um potente inibidor das proteínas tirosina quinase, que são receptores da insulina e sua ligação a estes receptores promovem o aumento da secreção de insulina [29].

A síndrome metabólica é caracterizada como um grupo de fatores de risco metabólicos como obesidade, dislipidemia e hipertensão arterial. Atualmente a obesidade é considerada uma doença metabólica que vem atingindo a população mundial e está sendo considerada como um grave problema de saúde pública. É uma forma de má nutrição que contribui para o surgimento de diversas doenças. $\mathrm{O}$ acúmulo excessivo de tecido adiposo na obesidade pode ser causado por fatores endócrinos, metabólicos, genéticos ou por alterações do gasto energético, devido à redução da atividade física e aumento do consumo dietético. Os adipócitos presentes em maior número e volume na obesidade apresentam aspectos funcionais importantes, pois atuam no metabolismo e homeostase energética, além de possuírem habilidade para adipogênese. A adiposidade central induz a inflamação crônica sistêmica, servindo de risco para desencadear a síndrome metabólica [33].
Atualmente, a soja vem sendo indicada nas intervenções nutricionais da obesidade, pois estudos mostram os benefícios que o consumo de alimentos à base de soja pode oferecer quando são introduzidos nas dietas com redução calórica. A ação benéfica da soja está relacionada com a promoção da melhora no metabolismo lipídico, a partir da ação dos fitoestrógenos da soja nos adipócitos e hepatócitos. Portanto, o conhecimento dessa substância e seus efeitos se faz necessário para o entendimento dos mecanismos dessas substâncias no processo fisiopatológico da obesidade. A soja é uma excelente fonte de arginina e glicina, aminoácidos importantes para a síntese de glucagon, que possui ação hiperglicemiante e termogênica e contribui para o aumento da oxidação dos ácidos graxos, via glicogenólise hepática [34].

Estudos têm demonstrado os efeitos do consumo da soja e seus fitoestrógenos no metabolismo do açúcar, lipídios e dos hormônios, a desordem do balanço energético e neuro-hormonal provocados pela obesidade pode induzir vários fatores de riscos como hiperinsulinemia, resistência à insulina e anormalidades no metabolismo lipídico. Em modelos experimentais em animais e humanos, a proteína isolada da soja e seus fitoestrógenos têm demonstrado reduzir os níveis de insulina sérica e a resistência à insulina. Em humanos obesos e animais, a soja, utilizada como fonte de proteína dietética, tem efeitos antiobesidade e hipocolesterolêmicos significativos [34].

\section{CONSIDERAÇÕES FINAIS}

Através do presente trabalho podemos concluir que o consumo da soja e seus derivados, fonte de isoflavonas, apresentam efeitos benéficos na prevenção do surgimento de doenças crônicas não transmissíveis como diabetes, hipertensão arterial e diversos tipos de câncer, além dos seus efeitos no controle dos sintomas da menopausa em mulheres.

Observa-se ainda, que mesmo com a grande produção agrícola brasileira, o consumo do grão e seus produtos derivados pela população ainda não é satisfatório, isso se deve tanto à falta de informação com relação aos benefícios do seu consumo, quanto pela falta de costume da população em consumir o grão como parte da alimentação usual.

O presente trabalho esclarece a população sobre os benefícios do consumo de grãos de soja e derivados e incentiva o consumo de tais produtos, a fim de prevenir doenças futuras, garantindo uma melhor qualidade de vida. 


\section{CONTRIBUIÇÃO AUTORES}

1. Levantamento bibliográfico e elaboração da revisão:

Mayara Miranda Zakir e Irene Freitas

\section{REFERÊNCIAS}

[1]. SILVA, M.R.; SILVA, M.A.A.P. Fatores antinutricionais: inibidores de proteases e lecitinas. Revista de Nutrição, v.13, p.3-9, 2000. http://dx.doi.org/10.1590/S141552732000000100001

[2]. PENHA, L.A.O.; FONSECA, I.C.B.; MANDARINO, J.M.; BENASSI, V.T. A soja como alimento: valor nutricional, benefícios para a saúde e cultivo orgânico. Boletim do Centro de Pesquisa de Processamento de Alimentos, v.25, p.91-102, 2007. http://dx.doi.org/10.5380/cep.v25i1.8397.

[3]. SILVA, C.E.; CARRÃO-PANIZZI, M.C.; MANDARINO, J.M.G.; LEITE, R.S.; MÔNACO, A.P. A. Teores de isoflavonas em grãos inteiros e nos componentes dos grãos de diferentes cultivares de soja (Glycine max (L.) Merrill). Brazilian Journal of Food Technology, v.15, p.150-156, 2012. 67232012005000008

http://dx.doi.org/10.1590/S1981-

[4]. ZAFRA-GÓMEZ, A.; GARBALLO, A. GARCÍA-AYUSO, L.E.; MORALES, J.C. Improved sample treatment and chromatographic method for the determination of isoflavones in supplemented foods. Food Chemistry, v.123, p.872-877, 2010 . doi:10.1016/i.foodchem.2010.05.009

[5]. BERNO, L.I.; LOPES, T.G.G.; BRAZACA, S.G. C. Avaliação da composição centesimal Digestibilidade e Atividade Inibitória de Tripsina em produtos derivados de soja (Glycine Max). Alimentos e Nutrição, v.18, p.277-282, 2007.

[6]. BEHRENS, J.H.; DA SILVA, M.A.A.P. Atitude do consumidor em relação à soja e produtos derivados. Ciência e Tecnologia de Alimentos, v.24, p.431-439, 2004.

[7]. KIRINUS, P.; COPETTI, C.; OLIVEIRA, V.R. Utilização de farinha de soja (Glycine Max) e de Quinoa (Chenopodium Quinoa) no preparo de macarrão caseiro sem glúten. Alimentos e Nutrição, v.21, p.555-561, 2010.

[8]. LIMA, E.C.S.; CARDOSO, M.H. Bebida de Soja (Glycine Max) e Acerola (Malpighia Punicifolia) enriquecida com cálcio. Alimentos e Nutrição, v.23, p.549-553, 2012.

[9]. MASUCHI, M.H.; CELEGHINI, R.M.S.; GONÇALVES, L.A.G.; GRIMALDI, R. Quantificação de TBHQ (Terc Butil Hidroquinona) e avaliação da estabilidade oxidativa em óleos de girassol comerciais. Química nova, v.31, p.1053-1057, 2008. http://dx.doi.org/10.1590/S010040422008000500020 .
2. Revisão final do artigo de revisão

Irene Rodrigues Freitas

[10]. HASLER, C.M. Functional Foods: Their Role in Disease Prevention and Health Promotion, Food Technology, v. 52, p.63-70, 1998.

[11]. SILVA, M.S.; NAVES, M.M.V.; OLIVEIRA, R.B.; LEITE, O.S.M. Composição química e valor proteico do resíduo de soja em relação ao grão de soja. Ciência e Tecnologia de Alimentos, v.26, p.571-576, 2006. http://dx.doi.org/10.1590/S010120612006000300014.

[12]. AZEVEDO, E. Riscos e controvérsias na construção social do conceito de alimento saudável: o caso da soja. Revista de Saúde Pública, v.45, p.781-788, 2011. http://dx.doi.org/10.1590/S003489102011000400019.

[13]. IKEDA, A.A.; MORAES, A.; MESQUITA, G. Considerações sobre tendências e oportunidades dos alimentos funcionais. Revista P\&D em Engenharia de Produção, v.8, p.40-56, 2010.

[14]. VIDAL, A.M.; DIAS, B.O.; MARTINS, E.S.M.; OLIVEIRA, R.S.; NASCIMENTO, R.M.S.; CORREIA, M.G.S. A ingestão de alimentos funcionais e sua contribuição para a diminuição da incidência de doenças. Cadernos de Graduação Ciências Biológicas e da Saúde, v.1, p.43-52, 2012.

[15]. AGENCIA NACIONAL DE VIGILÂNCIA SANITÁRIA - ANVISA. Alimentos com alegações de propriedades e ou de saúde, novos alimentos/ingredientes, substâncias bioativas e probióticos. 07/2008.

[16]. TEIXEIRA, A.C.M.; OELAME, C.S. O uso de alimentos funcionais no cotidiano e seus benefícios à saúde. Revista Científica do Colégio Militar de Curitiba, v. 5, n.1, 2013.

[17]. MARIN, M.; MADRUGA, N.A.; RODRIGUES, R.S.; MACHADO, M.R.G. Caracterização físicoquimica e sensorial de bebida proteica de soja. Boletim do Centro de Pesquisa de Processamentos de Alimentos, v.32, p.93-104, 2014. http://dx.doi.org/10.5380/cep.v32i1.36930.

[18]. MOREIRA, A.A.; MANDARINO, J.M.G.; NEVES-SOUZA, R. D. das.; LEITE, R. S.; OLIVEIRA, M. A. Teor de ácido fítico em cultivares de soja cultivados em diferentes regiões do estado do Paraná e São Paulo. Alimentos e Nutrição, v.23, p.393-398, 2012.

[19]. ESTEVES, E.A.; MONTEIRO, J.B.R. Efeitos benéficos das isoflavonas de soja em doenças crônicas. Revista de Nutrição, v.14, p.43-52, 2001. 52732001000100007 http://dx.doi.org/10.1590/S1415-

[20]. SIMÃO, A.N.C.; BARBOSA, D.S.; NUNES, L.B.; GODENY, P.; LOZOVOY, M.A.B.; DICHI, I. Importância da ingestão de soja nos sintomas do climatério, osteoporose e doenças 
cardiovasculares. Arquivos de Ciências da Saúde Unipar, v.12, p.67-75, 2008.

[21]. HE, F.J.; CHEN, J.Q. Consumption of soybean, soy foods, soy isoflavones and breast câncer incidence: Differences between Chinese women and women in Western countries and possible mechanisms. Food Science and Human Wellness, $\quad$ v.2, p.146-161, 2013. http://dx.doi.org/10.1016/j.fshw.2013.08.002.

[22]. BARNES, S.; KIM, H.; XU, J. Soy in the prevention and treatment of chronic diseases. In: CONGRESSO BRASILEIRO DE SOJA, 2, 2002, Foz do Iguaçu. Anais... Londrina: Embrapa, 2002. p. 295-308.

[23]. WATANABE, S.; UESUGI, S.; KIKUCHI, Y. Isoflavones for preservation of cancer, cardiovascular deseases, gynecological problems and possible immune potentiation. Biomedicine $\boldsymbol{\&}$ Pharmacotherapy, v.56, p.302-312, 2002.

[24]. GÓES-FAVONI, S.P.; BELÉIA, A.P.; CARRÃOPANIZZI, M.C.; MANDARINO, J.M.G. Isoflavonas em produtos comerciais de soja. Ciência e Tecnologia de Alimentos, v.24, p.582586, 2004.

[25]. BACHARI-SALEH， Z.; EZZATPANAH, H.; AMINAFSHAR, M.; SAFAFAR, H. The effect of refining process on the conjugated dienes in soybean oil. Journal of Agricultural Science and Technology, v.15, p.1185-1193, 2013.

[26]. ROSA，A.M.; CLAVISO, J.; PASSOS, L.M.; AGUIAR, C.L. Alimentos fermentados à base de soja (Glycine max (Merril) L.): importância econômica, impactos na saúde e efeitos associados às isoflavonas e seus açúcares. Revista Brasileira de Biociências, v.7, p.454-462, 2009.

[27]. CARVALHO, A.V.; GRACIA, N.H.P.; FARFÁN, J.A. Caracterização de concentrado e isolado proteico extraído de sementes de cupuaçu (Theobroma grandiflorum, Schum). Brazilian Journal of Food Technology, v.12, p.01-08, 2009.

[28]. RAMALHO, H. F.; SUAREZ, P.A.Z.A química dos óleos e gorduras e seus processos de extração e refino. Revista Virtual Química, v.5, p.2-15, $2013 . \quad$ http://dx.doi.org/10.5935/19846835.20130002.

[29]. PERON, A. P.; SANTOS, J.F.; MANTOVANI, D.; VICENTINI, V.E.P. Utilização das isoflavonas presentes na soja (Glycine $\max (L)$ Merril) na prevenção e tratamento de doenças crônicas - uma breve revisão. Arquivos do Mudi, v.12, p.50-57, 2008.

[30]. WEBER，K.S.; SETCHELL， K.D.; STOCCO, D.M.; LEPHART, E.D. Dietary soyphytoestrogens decrease testosterone levels and prostate weight without altering $\mathrm{LH}$, prostate 5 alpha-redutase or testicular steroidogenic acute regulatory peptide levels in adult male SpragueDawley rats. The Journal of Endocrinology, v.3, p.591-599, 2001.

[31]. ARALDI, E.M.; DELL'AICA, I.; SOGNO, I.; LORUSSO, G.; GARBISA, S.; ALBINI, A. Natural and synthetic agents targeting inflammation and angiogenesis for chemoprevention of prostat cancer. Current Cancer Drug Targest, v.8, p.146-155, 2008. http://dx.doi.org/10.2174/156800908783769382

[32]. WEI, P.; MING, L.; YAN, C.; DE CHAI, C. Systematic review of soy isoflavone supplements on osteoporosis in women. Asian Pacific Journal of Tropical Medicine, v.5, n.3. p.243-248, 2012. http://dx.doi.org/10.1016/S1995-7645(12)60033-9.

[33]. KANG, J.S.;LEE, W.K; LEE， C.W.; YOON, W.K.; KIM, N.; PARK, S.; LEE, H.; PARK, H.K.; HAN, S.; YUN, J.; LEE, K.; LEE, K.H.; PARK, S.; KIM, H.M . Improvement of high-fat dietinduced obesity by a mixture of red grape extract, soy isoflavone and L-carnitine: Implications in cardiovascular and non-alcoholic fatty liver diseases. Food and Chemical Toxicology. v.49, p.2453-2458, 2011. http://dx.doi.org/10.1016/j.fct.2011.06.071

[34]. PEIXOTO, J. C.; FEIJÓ, A.P.; SANTANA, A.B. Benefícios da soja no controle da Obesidade. Revista Eletrônica Novo Enfoque, v.12, p.47-67, 2011. 